\title{
O espaço público e a política moderna: uma análise das perspectivas de Carl Schmitt e Hannah Arendt
}

Mariah Lança de Queiroz Casséte

\begin{abstract}
Resumo
A proposta desse trabalho é estabelecer uma análise conceitual a respeito de como Carl Schmitt e Hannah Arendt desenvolveram uma concepção sobre a política fundada na ideia da publicidade, em contraposição ao predomínio da lógica privada e individualista dos sistemas liberais modernos. É interessante notar que os dois autores entendem o político como a linguagem de interação das pessoas que vivem conjuntamente e, por essa razão, ambos reconhecem a centralidade da vida pública e das ações que são desenvolvidas em seu interior. Apesar dessa convergência inicial, será ressaltado como cada um desses autores apresenta um entendimento peculiar a respeito do sentido e da constituição dessa esfera. Se na obra de Schmitt o foco da vida pública é a unidade e identidade coletiva, para Arendt o sentido desse espaço é a pluralidade e a prática dialógica.
\end{abstract}

Palavras-chave: Política. Espaço público. Carl Schmitt. Hannah Arendt.

\section{Introdução}

O pensamento político de Carl Schmitt e Hannah Arendt desafia as concepções contemporâneas tanto em relação ao tipo de constituição de um saber sobre a política, como em relação à maneira como a política é compreendida e realizada no mundo contemporâneo. De acordo com a perspectiva política hegemônica das sociedades modernas - o liberalismo -, a política é dotada de função e valor específicos: de administrar e organizar a interação entre as pessoas que vivem em comunidade, sem que isso signifique qualquer tipo de determinação sobre as outras esferas que compóem a vida social. Mais do que

Doutoranda e bolsista da CAPES/REUNI do Programa de Pós-Giraduação em Ciência Política da Universidade Federal de Minas Gerais (UFMG), Belo Horizonte, Minas Gerais, Brasil. É autora de artigos publicados na Revista Três [...] Pontos (UFMG, 2007, 2008).E-mail: mariahlqc@yahoo.com.br. 
isso: não há um valor especial na política que a torne mais importante que essas outras esferas. Seu papel é justamente permitir que a multiplicidade de grupos, associaçôes, interesses e motivaçóes possam conviver pacificamente dentro de uma ordem social que valoriza a liberdade privada e a igualdade de condiçóes.

Porém, a análise dos pensamentos políticos de Schmitt e Arendt mostra-nos perspectivas fundamentalmente distintas do pensamento liberal. De fato, algo que une a perspectiva desses dois autores em relaçáo à política moderna é a concepção de que a lógica liberal de compreender e organizar a política promove a mais intensa despolitização, acarretando uma série de problemas em termos de legitimidade na base das estruturas políticas vigentes e na forma como a política é dotada de sentido entre as pessoas.

O que gostaríamos de enfatizar nesse trabalho é um aspecto específico desenvolvido com enorme centralidade tanto por Carl Schmitt como por Hannah Arendt: a questáo do sentido público da política. É interessante notar que há uma concepção primordial no pensamento desses dois autores que se contrapóe diretamente à configuraçáo de uma lógica privada e instrumental que passa a predominar no campo da política liberal moderna. O que ambos defendem é uma noçáo do político que parte do fortalecimento e reconhecimento do espaço público como o espaço político por excelência. $\mathrm{O}$ argumento principal, nesse sentido, é o de que o universo liberal moderno produz um tipo de dinâmica coletiva que é pautada por uma lógica eminentemente privada, que promove ao centro da vida coletiva a busca pelo equilíbrio das necessidades egocêntricas individuais, baseando-se em leis e regras abstratas, que não possuem a menor correspondência com a existência concreta. A política, para esses autores, perde seu sentido quando transformada em mero mecanismo sujeito às demandas privadas, pois seu fundamento não pode ser outro senão o espaço público, isto é, a própria vida coletiva.

Sendo assim, para entender como ambos desenvolvem a noção de publicidade em suas obras é necessário analisarmos três aspectos básicos: primeiramente, é importante compreender como é desenvolvida a crítica ao liberalismo e a valorização do mundo público presente de forma profunda no pensamento tanto de Carl Schmitt como de Hannah Arendt. Entretanto, é importante náo apenas entendermos como é caracterizada essa centralidade do mundo público nos argumentos de ambos, mas também qual é o sentido e quais são os fundamentos que sustentam esse espaço público na perspectiva de 
cada autor. Por fim, cabe a introdução de uma reflexão a respeito da importância do resgate dessa categoria de publicidade para pensarmos as democracias contemporâneas. Nesse sentido, a questão que se coloca é a de se Schmitt e Arendt apresentariam princípios relevantes para se repensar não apenas o político, mas também o democrático.

\section{A política do indivíduo e o declínio do mundo público}

A perspectiva política predominante na consolidação das sociedades liberais é baseada em alguns pressupostos claros. Talvez o principal desses pressupostos seja a noção pluralista de que as sociedades modernas são marcadas por uma profunda diversidade de interesses e práticas. Tal diversidade se expressa na existência de uma multiplicidade de grupos e de esferas sociais, cada qual dotada de uma funçáo e de valor específico, mas nenhuma capaz de monopolizar as escolhas individuais. O pluralismo político entende a vida social como perpassada pelas mais diversas fontes de autoridade: indivíduos, família, associaçôes civis, instituiçôes religiosas e a própria política podem ser concebidas como instâncias que norteiam as práticas e concepçóes individuais, mas nenhuma delas possui um status de anterioridade ou superioridade em relação às demais. Isso significa que no contexto político do pluralismo liberal, é impossível estabelecer uma esfera mais relevante ou que seja capaz de centralizar em si mesma os principais valores e interesses dos indivíduos. Nesse sentido, o âmbito político é claramente compreendido como uma esfera importante que compóe a dinâmica da vida social, mas não pode ser concebida como portadora de nenhum tipo de autoridade especial que perdura sobre as práticas e escolhas dos indivíduos. Sendo assim, a política pluralista respeitaria as diversas esferas de associação humana e não contempla a si própria como o fundamento para essas atividades (GALSTON, 2005).

Desse modo, a política contemporânea é dotada de função e valor específico: o de administrar e organizar a interaçáo entre as pessoas, sem que isso signifique qualquer tipo de determinação sobre as outras esferas que compõem a vida social. Nesse sentido, não há um valor especial na política que a torne mais importante que essas outras esferas. Seu papel é justamente permitir que a multiplicidade de grupos, associaçóes, interesses e motivaçôes possam conviver pacificamente dentro de uma ordem social que valoriza a liberdade privada e a igualdade de condiçóes. $\mathrm{O}$ argumento que norteia essa perspectiva é o de 
O espaço público e a politica moderna: uma análise das perspectivas de Carl Schmitt e Hannah Arendt | Mariah Lança de Queiroz Casséte

que se a política e seu aparato institucional adquirirem prerrogativas mais ampliadas, há um perigo notório de que o fundamento básico do liberalismo seja ferido, isto é, a violação da liberdade que permite que indivíduos se associem de acordo com suas próprias preferências e cultivem as formas de vida que desejarem (BARRY, 1998).

Porém, a análise dos pensamentos políticos de Schmitt e Arendt mostra-nos perspectivas fundamentalmente distintas do pensamento liberal, apresentando uma concepção a respeito do âmbito político pautado na ideia de que essa esfera não apenas se distingue de outras esferas sociais em termos de sua especificidade e função, mas principalmente de um ponto de vista de valor e sentido. Hannah Arendt nesse ponto é incisiva: ao analisar a esfera das atividades humanas a autora parte de um pressuposto claro de distinção entre esfera privada e esfera pública. Porém essa diferenciação não se realiza apenas em termos de função. Seguindo o esquema filosófico aristotélico, Arendt distingue tais esferas em termos hierárquicos. $\mathrm{O}$ mundo privado é o lugar da necessidade e o mundo público - a política - é a esfera da liberdade humana, o que o torna, portanto, a esfera mais importante da vida activa. É em relação à importância da esfera pública que o termo "privado", em sua acepção original de privação tem significado. Para o indivíduo, viver uma vida inteiramente privada significa ser privado da realidade que advém do fato de ser visto e ouvido por outros, privado de uma relaçáo objetiva com eles e da possibilidade de realizar algo mais permanente que a própria vida: "a privaçáo do espaço privado reside na ausência de outros” (ARENDT, 2007, p. 68).

É importante ressaltar que a autora não destitui o mundo privado de valor, mas entende esse espaço como uma esfera incapaz de gerar liberdade, pois sua lógica é pautada exclusivamente nas categorias de meios e fins. Nesse contexto, não há espaço para a espontaneidade humana, uma vez que a lógica da determinação é aquela predominante. As atividades tipicamente privadas são aquelas que se constituem sempre como instrumentos para determinados objetivos, como a sobrevivência ou a produtividade, e podem ser realizadas sem a interação entre indivíduos. A lógica instrumental repousa sobre a necessidade constante de justificação de si mesma e, como afirma Arendt: aquilo que carece de justificação não pode ser essência de coisa alguma.

É por essa razão que o espaço público adquire autonomia e centralidade na perspectiva da autora. Essa esfera só existe no encontro entre cidadãos, não 
é um meio para outros fins mais importantes, e sua configuração é sempre indeterminada. A pluralidade e a espontaneidade encontradas nesse âmbito geram um espaço de liberdade e equidade entre as pessoas, espaço esse pautado sempre pela possibilidade de novos começos transformadores. A esfera pública se distingue em natureza e em valor em relação à esfera privada e suas atividades. Isso porque, ao contrário do que concebem os sistemas liberais, a política não é mais uma esfera da vida social entre outras, mas a única capaz de constituir um mundo em comum entre as pessoas, não apesar de suas diferenças, mas por meio delas.

O problema da modernidade é que a autonomia e a centralidade da política são minadas na medida em que as necessidades e a própria lógica privada invadem a dinâmica da esfera pública. Vale notar que o que a autora denomina "emergência do social", em $A$ condição humana (ARENDT, 2007), não é simplesmente o fato de que as questóes privadas emergem no espaço público ${ }^{2}$. Mais importante que isso, é que a emergência do social diz respeito ao fato de que a própria lógica instrumental, típica da esfera privada, passa a ditar os assuntos políticos. Nesse sentido, a produção e acumulação econômica tornam-se prioridade de governos, e cada decisão, cada ação política é submetida a essa dinâmica. Além disso, o Estado se transforma em uma instância de provisão que existe para satisfazer as necessidades dos cidadãos e produzir leis e regras que viabilizam uma convivência social pacificada. Por fim, as próprias estruturas dos sistemas políticos modernos passam a se basear em termos de meios e fins. A administração pública e a burocracia partem exatamente do pressuposto de buscar os meios mais eficientes para garantir que os processos sociais se desenvolvam sem contratempos; e a representaçáo política - pilar da democracia liberal - parte da noção de que o representante é aquele que adentra no mundo da política para assegurar que os interesses de seus representados sejam levados em conta nas açóes governamentais, baseando-se, assim, na lógica instrumental. A administração, a burocracia e a representação seriam, para Arendt, pré-políticas em sua natureza, exatamente por imporem aos assuntos públicos uma lógica utilitária de necessidade, destruindo assim a pluralidade e a espontaneidade da ação humana (VILLA, 1996).

2 Hannah Pitkin (1998), Iris Young (1998) e Sheldon Wolin (1994) são exemplos de autores que interpretam essa categoria do "social" na obra arendtiana como uma crítica da autora ao processo de disseminação de questões privadas no âmbito da esfera pública. 
A despolitização moderna, de acordo com Arendt, não ocorre porque os assuntos privados invadem a esfera pública, mas porque a lógica instrumental da esfera privada torna-se a lógica do mundo e das instituiçóes políticas. A necessidade e a determinação passam a ditar a dinâmica pública, destituindo-a de sua natureza plural e imprevisível e, consequentemente, reduzindo-a a um mero campo social entre outros. Dessa forma, perde-se a política e, com ela, a possibilidade do poder conjunto, capaz de legitimar e fundamentar os processos legislativos e decisórios. Isso porque a açáo genuinamente política nunca é um meio para se alcançar objetivos de vida, mas a possibilidade de dotar a vida conjunta de sentido e valor.

Carl Schmitt, mesmo que partindo de uma perspectiva distinta de Arendt, também critica as sociedades modernas apontando o fato de elas promoverem uma profunda despolitização. Mais uma vez, o problema em questão é o modo como a política é compreendida e incorporada nos sistemas sociais. Cabe lembrar que o cerne daquilo que Schmitt compreende como o político baseia-se na distinção entre amigo-inimigo, na real possibilidade do conflito entre agrupamentos humanos distintos e, consequentemente, na consolidação de uma unidade que só pode ser constituída na existência da oposição.

$\mathrm{Na}$ visão do autor, a condição do político é existencial: a vida em sociedade é estruturada concretamente por meio de diferenciaçóes que unem e separam coletividades. De acordo com Schmitt, rejeitar essa realidade náo vai fazer com que o político desapareça do mundo, mas apenas enfraquecer os povos que insistem em ignorá-lo (SCHMITT, 1996).

O político, nesse sentido, não é mais uma esfera que compóe a vida social e que está submetida aos interesses dos mais diversos grupos. $\mathrm{O}$ fato é que o político apresenta um status de anterioridade em relação às outras facetas da dinâmica social. Isso ocorre porque é ele que caracteriza o ponto máximo do antagonismo e a possibilidade real do combate entre grupos. E é exatamente esse caráter extremo que permite a definição dos critérios que definem a estrutura normativa capaz de produzir uma ordem coletiva legítima. Sem a polarização política amigo-inimigo torna-se impossível uma identificação efetiva daqueles valores que unem e separam as pessoas em coletividades e que dota de sentido suas açóes e seu comportamento.

A lógica do político, portanto, é um dado que se impõe nas relaçôes humanas e nas interaçôes coletivas. Negar a centralidade e autonomia do político 
é negar a possibilidade de fundamentação da ordem social em um conjunto de valores normativos que concretamente definam a identidade coletiva e que façam sentido aos membros de um grupo. Uma sociedade que nega o político torna-se, portanto, incapaz de oferecer direção à sua própria existência (FERREIRA, 2004).

Porém, na perspectiva de Schmitt é exatamente esse fato que marca a lógica dos sistemas liberais modernos, ou seja, a incapacidade apresentada pelas naçôes de serem autônomas e guiarem efetivamente seus próprios caminhos. O liberalismo partiria da premissa de valorização exacerbada do indivíduo e da pressuposição de que a ordem social seria resultado das relaçóes pacíficas entre eles. Essa noçáo tem origem em um pensamento egocêntrico típico da modernidade, pensamento esse que parte da concepção de que o sujeito emancipado liberal é o senhor de si mesmo e vivencia a realidade também como uma experiência subjetiva privada e ocasional ${ }^{3}$.

Carl Schmitt aponta uma série de convicçóes liberais que revelam essa concepçáo de que seria possível encontrar uma ordem efetiva a partir da própria dinâmica da interação social: o tipo de direito estabelecido, a confiança profunda na razão, a centralidade do debate, a força da concorrência e do mercado econômico, a primazia da técnica. Todos esses aspectos reforçariam essa ideia de imanência da ordem e reduziriam o papel da política no contexto social. De fato, a concepção moderna de que a ordem coletiva é autorregulada faz com que a política seja compreendida como uma esfera da vida social responsável exclusivamente por criar mecanismos para permitir a convivência pacífica entre os indivíduos. A política precisa apresentar-se como esfera neutra, apenas reguladora das interações individuais, mas não possui qualquer prerrogativa no sentido de nortear as ações e decisóes públicas. Nesse sentido, o liberalismo emerge como paradigma de extrema compatibilidade a tais aspiraçôes. $\mathrm{O}$ sistema social liberal, desde sua origem, apresenta-se por

3 A entronização do sujeito como centro originário de entendimento e de produção da realidade é radicalizada no contexto do Romantismo, que promove a subjetividade ao mais alto nivel e torna-a a grande fonte para o ordenamento da realidade. O problema é que a subjetividade confinada aos limites individuais é incapaz de conferir forma substancial à realidade, afetando profundamente o tipo de compreensão a respeito do político e da vida pública nas sociedades modernas. Schmitt discute as origens e fundamentos dessa mentalidade romântica moderna no liuro $\mathrm{O}$ romantismo político, que apesar de relevante para a compreensão do tipo de mentalidade do individuo moderno e suas consequências sobre o político, não foi incluída com mais profundidade neste trabalho. 
O espaço público e a politica moderna: uma análise das perspectivas de Carl Schmitt e Hannah Arendt | Mariah Lança de Queiroz Casséte

meio de uma posição crítica e de desconfiança da política e suas instituiçôes. Essa perspectiva crítica do liberalismo em relação à política parte da noção de que qualquer tipo de interferência na lógica de autorregulação das sociedades, qualquer ação sobre a livre competição é considerada repressiva. Sendo assim, a política náo pode ter nenhuma função que não seja procedimental, destituída de conteúdo efetivo, baseada na neutralidade e na eficiência da técnica. Schmitt aponta que, com o propósito de proteger a liberdade individual e a propriedade privada, o liberalismo fornece uma série de métodos para esconder e controlar o poder do Estado. Ele, assim, faz do Estado um espaço de comprometimentos e de suas instituições um sistema de ventilação.

O grande problema nesse contexto é a suposição de que a imanência da vida pública liberal seria capaz de produzir uma ordem social. A negação da existência conflitiva e antagônica do político náo faz com que ele desapareça, mas permite que outras esferas da vida social tomem seu lugar como campos supostamente condutores das atividades e decisóes públicas. O ponto de vista do político passa a ser subjugado pela economia, pela moral e pelo direito; além disso, o Estado torna-se um local de disputa entre os interesses dos mais distintos grupos e perde sua centralidade no direcionamento da ordem coletiva.

Dessa forma, a busca por uma lógica social pacífica e neutra, capaz de ordenar a si mesma, teria, na perspectiva do autor, a consequência de incapacitar o estabelecimento de diferenciaçóes e de qualquer tipo de justificativa capaz de ordenar normativamente a existência coletiva. O compromisso entre interesses, característica da lógica liberal, esconde, na verdade, o fato de que sempre há um grupo comandando e influenciando os rumos coletivos concretos (SCHMITT, 1999). A grande falha liberal é sua incapacidade de identificar tal influência, sujeitando a vida social ao interesse particularista de poucos e produzindo uma ordem ilegítima e totalmente incapaz de decisão em qualquer contexto que não seja o de normalidade. Para Schmitt, a despolitização promovida na modernidade, ao negar o político, impossibilita autonomia coletiva e possibilidade de ordem efetiva.

É possível perceber que as concepçôes de Carl Schmitt e de Hannah Arendt a respeito da dinâmica política moderna se aproximam, principalmente, no que diz respeito à percepção do lugar e valor da política em relação aos outros aspectos da vida social. Ambos os autores consideram a política mais do que simplesmente uma entre outras esferas das sociedades modernas, mas 
como o âmbito central das relaçóes humanas, dotado de autonomia e anterioridade em relação a outros tipos de atividades. A política é a origem da possibilidade de uma vivência coletiva. Política é aquilo que torna uma multiplicidade de indivíduos, dotados de interesses e ideais distintos, uma comunidade, ou seja, a política tem como fonte e estrutura a coletividade.

Schmitt e Arendt também realizam duras críticas ao sistema liberal moderno, que, na visão dos autores, é responsável por produzir uma despolitização profunda da vida social, devido justamente à minimização e desvalorização do público em favor de uma exacerbada exaltação do espaço privado. Sendo assim, apesar da diferença no significado que a política apresenta no interior da perspectiva de cada um desses autores, há em comum entre eles a noção central de que a política nunca pode ser considerada mera derivação da dinâmica social, pois de fato é ela a responsável por atribuir sentido às açóes e processos desenvolvidos pelas pessoas que vivem em comunidade. $\mathrm{Na}$ perspectiva de ambos, quando falamos em política estamos sempre nos referindo ao aspecto público da vida, e não à esfera privada.

\section{Unidade ou pluralidade?}

Como foi analisado, há esse importante ponto de partida em comum nos pensamentos políticos de Schmitt e Arendt, que diz respeito à crítica ao liberalismo e também ao processo de privatização da política moderna e ao declínio do público nas sociedades de massa. Ambos os autores atribuem relevância central ao fortalecimento do espaço público e da comunidade política. No entanto, é preciso salientar que o sentido e a configuração do espaço público apresentam significado e ressonâncias distintos para cada um deles. Nesse sentido, ainda que seja possível percebermos tanto em Schmitt quanto em Arendt a valorização do público em oposição à fragmentação privada e individualista do liberalismo, a maneira como eles entendem tal categoria é extremamente distinta. Apesar do fato de ambos recuperem uma ideia da política fundada na vida comum, cada um deles pensa esse espaço comum por meio de princípios diferentes. É importante, portanto, analisarmos como ocorre tal distinção.

Ao pensar o político, Carl Schmitt apresenta um objetivo básico: compreender a natureza da vida em comunidade. O político, para o autor, se estabelece na definição daquilo que cria e reproduz a vida conjunta - as bases de sua existência e legitimidade. Desse modo, Schmitt aponta que o critério 
O espaço público e a politica moderna: uma análise das perspectivas de Carl Schmitt e Hannah Arendt | Mariah Lança de Queiroz Casséte

fundamental que define o político é o antagonismo existente entre agrupamentos sociais, ou seja, a distinção entre amigo e inimigo. Essa antítese definidora não se reduz e não pode ser confundida com definiçóes de outros domínios, como o bem e o mal (moral) ou o lucro e o prejuízo (economia), e por essa razão tal critério do político é único e o diferencia como esfera autônoma da realidade humana.

Esse antagonismo entre amigo e inimigo remete à possibilidade real e concreta do conflito. Tal distinção indica o nível da intensidade de uma união ou de uma separação, de uma associação ou de uma dissociação. Assim, quanto mais intenso e mais extremo é o antagonismo entre grupos, maior é o grau do político:

O político é o grau mais intenso e extremo de antagonismo, e todo antagonismo concreto se torna mais político à medida que se aproxima de seu ponto mais intenso, o ponto de diferenciação entre amigo e inimigo [...]. Os conceitos de amigo e inimigo recebem seu sentido efetivo precisamente por se referirem a uma possibilidade real de confronto físico ${ }^{4}$. (SCHMITT, 1996, p. 33, tradução nossa).

Quando o autor define o conceito de político como o antagonismo amigo e inimigo, ele não está se referindo à mera existência da competiçấo entre indivíduos no âmbito social, nem a controvérsias intelectuais, tampouco a uma luta simbólica. O político é uma condição existencial que caracteriza o antagonismo como fundamento posicional das pessoas no mundo e também umas perante as outras. $\mathrm{O}$ conflito, nesse sentido, indica a possibilidade real do confronto, ou seja, a possibilidade da guerra. Isso náo significa que o confronto armado é o conteúdo da política ou o principal objetivo da política, nem tampouco isso significa que "a guerra é a continuação da política por outros meios"s. Para Schmitt, a guerra nada mais é que o resultado extremo de uma decisão política. De fato, é resultado da decisão política por excelência: a delimitação daqueles que são amigos e aqueles que são os inimigos. Tal decisão é o fundamento sobre o qual se delineia a forma como as

4 "The political is the most intense and extreme antagonism, and every concrete antagonism becomes that much more political the closer it approaches the most extreme point, that of the friend enemy grouping [...]. The friend. enemy concepts receive their real meaning precisely because they refer to the real possibility of physical killing".

5 Essa frase de Clausewitz é questionada pelo próprio Schmitt no primeiro capítulo do liuro O conceito do político (SCHMITT, 1996). 
sociedades se organizam e de como as pessoas vivem em seu interior. Como aponta Bernardo Ferreira (2004), no conceito do político de Schmitt, a guerra não é compreendida como condição normal da vida pública, e nem mesmo das relaçóes entre naçóes, o combate é ocasião extraordinária. O que torna o conflito o princípio central do político é justamente a possibilidade de ele vir a se concretizar, o seu caráter extremo e limítrofe, que gera um tipo específico de comportamento e um tipo específico de organização de coletividades.

Desse modo, não se pode constatar que haja um conteúdo determinado do político, não se podem identificar categorias ou elementos que o preencha: não há uma substância própria nesse conceito. É importante esclarecer esse ponto, uma vez que o político precisa ser compreendido como uma linguagem que estrutura as relaçôes humanas. Independentemente da razão ou dos motivos pelos quais as pessoas se dividam, o que realmente importa do ponto de vista político é o modo de comportamento gerado pela dissociação. $\mathrm{O}$ antagonismo, portanto, é a condição do político, mas o motivo, o conteúdo desse antagonismo pode ser das mais diversas naturezas: toda oposição religiosa, moral, econômica, étnica, entre inúmeras outras, torna-se oposição política quando é suficientemente intensa para agrupar seres humanos entre amigos e inimigos. Se oposiçóes étnicas, econômicas ou de qualquer outra natureza conduzem ao confronto, é porque elas já deixaram de ser meramente econômicas, étnicas e se tornaram políticas, pelo fato de adquirirem a intensidade necessária para agrupar pessoas como amigas e inimigas (ARDITI, 2008).

Desse modo, para Schmitt, é impossível pensar no político excluindo-se a presença do conflito, já que este se torna também a condição da associação política. $\mathrm{O}$ que queremos dizer é que o antagonismo político define não apenas o inimigo, mas também quem é o amigo. E isso não é banal, uma vez que em contraposição ao inimigo torna-se possível a existência da definição de uma identidade coletiva. A definição recíproca de amigos em relação a inimigos apresenta-se como uma forma de produçáo de identidade. A esfera a partir da qual o grau de intensidade do antagonismo político é atingido se torna o eixo constitutivo da identidade coletiva (FERREIRA, 2004).

Diferente das premissas clássicas do liberalismo político, o campo do político não é um mero instrumento para que as garantias dos direitos e liberdades individuais estejam asseguradas, mas é o âmbito, por excelência, em que a convivência coletiva é ordenada e definida. Ou, em outras palavras, o político 
diz respeito à formação de uma unidade social, detentora de uma identidade específica, que propicia a existência de uma esfera normativa de valores e princípios que a possam ordenar.

É necessário nos determos nesse argumento. Como foi exposto anteriormente, de acordo com Schmitt, o político diz respeito ao antagonismo concreto entre grupos que se dividem pela oposição amigo/inimigo. Essa oposição entre grupos não apenas define quem é o inimigo público, mas mais importante que isso: ela define as características e o limite da própria comunidade. Isso, por sua vez, indica que o político não representa simplesmente o grau de dissociação entre coletividades, mas também o grau de associação de um grupo, ou seja, a intensidade de sua unidade.

Percebe-se aqui que a unidade é noção central do conceito do político. De fato, o político, apesar de não possuir nenhum conteúdo próprio (isto é, não há nenhum tipo de definiçáo a respeito de quem deve ser encarado como o inimigo), é responsável por gerar um tipo de configuração coletiva e de espaço público que apresenta como consequência, justamente, a conformaçáo da unidade social. Desse modo, quando se distingue de outro grupo, a comunidade pode definir a si própria, por meio de uma identidade unívoca e coletiva. O conceito do político enfatiza a dimensão existencial do antagonismo e da dissociação e, a partir de tal premissa, revela que o homem é membro de coletividades que são levadas a se definir em oposição a outras coletividades, fato que determina a sua própria razáo de ser (FERREIRA, 2004). Podemos inferir que, no que diz respeito à política externa, a lógica da inimizade e do confronto é aquela que delimita os tipos de açóes empreendidas coletivamente. Porém, no que se refere à política interna a lógica determinante é a da amizade, que remete à unidade e à identidade coletiva.

Sendo assim, de acordo com Schmitt, não é a partir de princípios abstratos universais que uma comunidade adquire as regras, normas de convivência e valores que a caracterizam. O universalismo liberal, que defende a existência de formas políticas comuns a todos os povos, é duramente criticado pelo autor - o político náo pode englobar a humanidade como um todo. A humanidade não é um conceito político e nenhuma entidade política, nenhuma sociedade e nenhuma identidade única correspondem a ela. Seria impossível imaginar uma comunidade política universal, baseada em uma série única de princípios, valores e normas. Isso seria totalmente contra a natureza do político, já 
que este se baseia justamente na complexidade, na diversidade e nos antagonismos presentes na realidade concreta da existência humana. Como afirma o autor, "a universalidade a qualquer preço significaria uma total despolitização, além da impossibilidade de existência de Estados" ${ }^{6}$ (SCHMITT, 1996, p. 55, tradução nossa).

Para Schmitt, a inclusão forçada dos antagonismos sociais, em uma perspectiva política normativa universal, tem como efeito nada menos do que a própria exclusão do político como fonte de ordenamento social, e isso significa a própria impossibilidade de uma ordem comum efetiva. A fragmentação individualista promovida pelo paradigma liberal parte da premissa de que a esfera da política, por meio da técnica e de procedimentos, é capaz de estruturar a organização social de modo que as sociedades adentrem uma lógica imanente, imparcial e aparentemente pacífica de autogoverno. Mas, para o autor, essa lógica simplesmente ignora a contingência da realidade, ou seja, a existência da diferença e do antagonismo entre agrupamentos humanos, bem como o fato de que em momentos extremos o caráter abstrato e simplista de normas universalizantes não é capaz de garantir nem a ordem, nem tampouco a unidade coletiva. $\mathrm{O}$ que esse argumento indica, no limite, é que a lógica imanente e abstrata de ordenamento coletivo instaurada no sistema liberal despolitiza comunidades e, consequentemente, enfraquece-as como coletividades, ou como naçóes.

É importante ressaltar que, na perspectiva do político, os princípios de legitimidade e ordenamento coletivo não podem ser derivados de uma lógica normativa preexistente. O que Schmitt propóe é exatamente o oposto: é necessário que primeiramente a coletividade se reconheça como detentora de uma identidade específica para, só então, estruturar os princípios e elementos que a ordenarão. É por essa razão que os chamados princípios políticos universais falham em propiciar unidade e legitimidade a agrupamentos humanos, uma vez que pressupóem que a ordem e a unidade coletiva são consequências naturais da adoção a um determinado conjunto de normas preestabelecidas para toda a humanidade, quando de fato deveriam ser o fundamento para a própria estruturação da norma.

6 No original: "Universality at any price would necessarily have to mean total depoliticalization, and with it, particularly, the nonexistence of states". 
Sendo assim, podemos interpretar que na concepção de Schmitt sobre o político a unidade é compreendida a partir do pressuposto da convergência, da homogeneidade entre as pessoas de um grupo, de um povo. Os amigos, nesse sentido, são aqueles capazes de compartilhar uma perspectiva de mundo semelhante, bem como um conjunto de valores e princípios convergentes. A homogeneidade no pensamento de Schmitt diz respeito a uma igualdade existencial entre os membros de uma coletividade, capaz, assim, de garantir sua unidade (PREUSS, 1999). O político situa, posiciona, define coletividades, direcionando efetivamente a ação destas no mundo. Os indivíduos na realidade coletiva partilham valores que ordenam seus atos, suas concepçóes e, consequentemente, direcionam suas decisões. Para Schmitt, é impossível que haja uma esfera normativa na convivência humana - isto é, valores, princípios e regras de conduta que dirijam nossa existência em comunidade - sem que as pessoas se reconheçam como parte de uma mesma comunidade. A ordem política, nesse sentido, requer a existência da unidade; e a unidade, por sua vez, pressupóe a existência de uma identidade coletiva, partilhada pelos membros de um grupo.

É possível concluir, portanto, que no pensamento schmittiano o político fundamenta-se na existência e no fortalecimento de uma comunidade entre iguais e de um sentido público homogêneo e concreto.

Se o princípio do político e o sentido do público, para Schmitt, partem da ideia de unidade, é muito interessante constatar que para Hannah Arendt a política e a esfera pública são nada menos que uma atualização do fato da pluralidade. De acordo com a autora, a condição especificamente humana é o fato de que "ninguém é exatamente igual a qualquer pessoa que tenha existido, exista ou venha a existir" (ARENDT, 2007, p. 16). Nesse sentido, a política é a possibilidade de que essa pluralidade seja explorada em toda sua potencialidade, ou seja, é o modo pelo qual os indivíduos se manifestam diante uns dos outros e podem plenamente compreender, ser compreendidos e conceber o mundo que os rodeia de forma mais ampla - pautados náo apenas em uma visão única e individualizada, mas por múltiplas perspectivas.

Nesse sentido, o mundo público só pode ser constituído a partir da multiplicidade de opinióes e de pontos de vistas. Isso porque é na diferença entre os indivíduos que se torna possível encontrar o que existe em comum entre eles. Com efeito, se analisarmos o contexto político moderno, é possível identificar 
uma emergente falta de legitimidade e enfraquecimento dos sistemas políticos e do espaço público (LEYDET, 2004). E o argumento arendtiano entenderia tal processo como consequência do fraco envolvimento da diversidade dos cidadãos nos assuntos públicos. Com efeito, o entendimento da política como uma esfera profissional especializada (WEBER, 1970) e da democracia como um procedimento minimalista (SCHUMPETER, 1984) torna esse sistema de governo privilégio de uma pequena minoria de pessoas, liderada por interesses de grupos específicos. No entanto, é inegável que um dos principais aspectos que distingue a democracia dos outros tipos de regime é justamente o fato de que ela requer um nível significativo de publicidade e inclusão da pluralidade na vida pública, princípio defendido por Arendt como fundamental para a prática política.

A autora explicita esse fator de maneira bastante clara no livro $A$ condição humana (ARENDT, 2007), mostrando como o espaço político nasce entre as pessoas quando estas se reúnem em liberdade, trazendo consigo suas singularidades e sua própria maneira de ver o mundo e de se portar no mundo. De acordo com ela, a visibilidade é o que constitui a realidade das coisas. Tudo aquilo que aparece e é compartilhado em público entre os cidadãos pode ser visto e ouvido por todos, e toda essa exposição acaba por revelar aspectos que nunca poderiam ser revelados se não fosse tal aparição pública. É a variedade de perspectivas e de pontos de vista que permite que um mesmo objeto, ou uma mesma situação, se torne mais completa e verossímil do que se permanecesse escondida da luminosidade pública. Essa metáfora, utilizada constantemente por Arendt, da intensa "luz" da esfera pública decorre justamente do fato de que o mundo se abre de maneira diferente a cada pessoa, e é na reunião e discussão dessas diferentes experiências que o mundo pode ser mais plenamente conhecido, ou mais completamente abarcado. Ou seja, apenas na pluralidade humana e na plena manifestação de tal pluralidade é possível abarcar mais claramente a realidade em toda a sua profundidade e complexidade:

Somente quando as coisas podem ser vistas por muitas pessoas, de sorte que os que estão à sua volta sabem que vêem o mesmo na mais completa diversidade, pode a realidade do mundo manifestar-se de maneira mais real e fidedigna [...]. A destruição do mundo comum é geralmente precedida pela destruição dos muitos aspectos nos quais ele se apresenta à pluralidade humana (ARENDT, 2007, p. 67). 
Essa abertura para o mundo nada mais é do que a própria experiência política. A política permite aos indivíduos se moverem no "terreno sólido da realidade" e, consequentemente, viverem na liberdade de conhecer e construir o mundo em suas mais diversas facetas. $\mathrm{O}$ espaço público da política permite que os indivíduos se aproximem - ao construírem um mundo em comum entre eles - sem, no entanto, colidirem, ou seja, mantendo uma distância mútua que permite a manifestação de suas próprias singularidades e a manutenção da diversidade entre si.

A política, nesse sentido, não se encontra de forma alguma nos próprios indivíduos envolvidos nessa dinâmica dialógica de desvelamento da realidade, ou seja, não é um dom interno de cada pessoa, mas se estabelece nesse espaço público que é formado quando essas pessoas agem conjuntamente, um espaço da palavra e da ação (LAFER, 2003). Onde quer que as pessoas se reúnam em liberdade, um mundo comum surge entre elas, e é nesse espaço que todos os assuntos humanos são conduzidos. Entende-se, assim, a razão pela qual Arendt aponta a política como atividade puramente humana por excelência, aquilo que nos distingue de todas as outras espécies, configurando-se como fator livre das leis da natureza, rompendo com a existência meramente cíclica da vivência física e biológica e dotada de potencialidade, de permanência e durabilidade que nenhuma outra esfera da vida possui: "É o caráter público da esfera política que é capaz de absorver e dar brilho através dos séculos a tudo que os homens venham a preservar da ruína natural do tempo" (ARENDT, 2007, p. 65).

Esse espaço público se contrapóe àquilo que a autora denomina de esfera privada da vida humana, compreendida como o espaço da necessidade, da força, da hierarquia e da naturalidade. $\mathrm{Na}$ esfera privada, a condição de sobrevivência da espécie é aquela que delineia e determina suas principais características - o seu aspecto cíclico, volátil e fugaz. Na privacidade não há e nem pode haver a pluralidade, pois a lógica desse espaço é a da preservação da própria vida. Assim, não há construção de nada novo e durável, não há a possibilidade de adquirir uma permanência mundana para a vida, nem de romper os laços das necessidades biológicas e da dinâmica cíclica dos processos vitais, imprimindo uma linearidade significativa que sobreviva à própria existência individual. $\mathrm{O}$ que se verifica na esfera privada é justamente a privação: mais especificamente, é a privação da convivência com os outros, é a privação da possibilidade de ir a público e ser visto e ouvido por todos e, portanto, é a 
possibilidade de perda de referência com a própria realidade ${ }^{7}$. Falta ao domínio privado o elemento fundamental da vida política: falta o 'outro' para se dialogar, para se exercer a alteridade e para construir um mundo em comum, por meio da ação humana praticada por pessoas (sempre no plural). É apenas no espaço público que a política pode existir e propiciar um contexto de autonomia e transformaçáo.

Podemos compreender, portanto, que a categoria de publicidade tem relevância primordial no pensamento de Schmitt e de Arendt. Contrários à premissa individualista do liberalismo, os dois autores recuperam a centralidade do coletivo como fonte primeira da constituição política. No entanto, o autor desenvolve sua ideia de publicidade tendo como fundamento o elemento da unidade: para ele o espaço público caracteriza a prevalência da homogeneidade e de uma identidade coletiva concreta, capaz de dotar a vida comum de sentido, força e efetividade. Já o ponto de partida arendtiano em relação ao espaço público é completamente distinto: ao invés de pensar a homogeneidade como fundamento do político, a autora defende que é a pluralidade, a diversidade aquilo que constitui o sentido e a própria possibilidade da vida pública.

\section{O público e a democracia: apontamentos finais}

As abordagens conceituais de Carl Schmitt e Hannah Arendt, como analisamos, apresentam como fundamento uma revalorização da vida pública em meio à realidade marcada por um processo profundo de despolitização. Para eles, a política náo pode ser considerada como mais uma esfera entre outras da vida social, ela é dotada de autonomia e anterioridade, não pode estar encarregada de uma função específica. Assim, a política deve ser interpretada como realidade central da vida coletiva dos membros de um determinado grupo, capaz de possibilitar uma existência autônoma e fortalecida à coletividade. Porém, o resgate de um sentido público náo passa pelas mesmas premissas em se tratando do pensamento desses autores: se para Schmitt a valorização pública estrutura-se na ideia da unidade e na conformaçáo de uma identidade coletiva concreta, para Arendt a constituição e possibilidade de um espaço público fortalecido funda-se na pluralidade e na diversidade de opiniôes, perspectivas

7 Não podemos, no entanto, interpretar esse espaço de privações como um espaço irrelevante na teoria arendtia na (BENHABIB, 2003), já que a autora atribui importância fundamental a ele afirmando que a esfera pública não pode existir sem esse espaço privado, de modo que a supressão de um gera consequentemente o risco de perda do outro. 

Queiroz Casséte

e pontos de vistas - apenas através da diferença é que se torna possível estabelecermos um mundo comum.

A categoria do público, táo relevante para pensarmos o político nas obras de Schmitt e Arendt, pode também ser de enorme importância para pensarmos o democrático. O que é importante enfatizar é que as democracias contemporâneas têm sido confrontadas com transformaçóes econômicas, culturais e sociais que trazem uma série de novas questóes e desafios para a realização pública de um ideal democrático mais profundo e renovado (ROSANVALLON, 2006).

Nesse sentido, cabe incluirmos nas reflexôes sobre a democracia uma atenção mais contundente à questão da publicidade em contraposição ao predomínio do privado na lógica de nossos sistemas liberais representativos. Como foi analisado ao longo deste texto, as obras de Schmitt e Arendt sáo incisivas nesse ponto: o universo liberal moderno produz um tipo de dinâmica coletiva que é pautada por uma lógica eminentemente privada, que promove ao centro da vida coletiva a busca pelo equilíbrio das necessidades egocêntricas individuais, baseando-se em leis e regras abstratas, que não possuem a menor correspondência com a existência concreta. A política, para esses autores, perde seu sentido quando transformada em um mecanismo meramente sujeito às demandas privadas, pois seu fundamento não pode ser outro senão o espaço público. $\mathrm{O}$ político diz respeito àquilo que constitui a coletividade, ao reconhecimento daquilo que nos une e daquilo que nos distingue uns dos outros. Considerar a definiçáo da política como originária no espaço público atribui validade e legitimidade aos princípios normativos que constituem a existência coletiva.

Isso porque, sendo o conflito ou a ação conjunta a origem da política, ambos apresentam o mesmo fundamento: são capazes de estabelecer um mundo em comum entre as pessoas e de estruturarem aquilo que é relevante e que faz sentido para a coletividade. Dessa perspectiva, se a origem do político encontra-se no mundo público, a democracia, entáo, é impensável fora dessa esfera. Entender o espaço público como o centro da dinâmica de ação e decisão da vida conjunta permite que a construção da identidade coletiva seja totalmente compartilhada, o que garante um fundamento normativo capaz de unir os cidadãos sem, no entanto, deixar de estar sujeito a transformaçóes e demandas que se originam a partir dessa mesma coletividade.

Contudo, é necessário especificarmos que tipo de entendimento a respeito do público cabe no contexto de uma linguagem democrática. Nosso 
posicionamento é o de que não é possível considerarmos a categoria de Carl Schmitt como um fundamento adequado para tanto. Isso ocorre porque o foco exclusivo na unidade coletiva é insuficiente para tratar da questáo, cada vez mais presente na contemporaneidade, que se resume na seguinte premissa: como incluir as diferenças e a diversidade nos processos de construção da realidade pública? Não é possível compartilhar com Carl Schmitt sua valorização extrema da homogeneidade como base para o estabelecimento da democracia. Por mais que um sentido público de identidade contribua para uma ordem política mais legítima e compatível com os valores compartilhados pelos cidadãos, o entendimento da democracia como "eliminação ou erradicaçáo da heterogeneidade" (SCHMITT, 1992) choca-se com uma realidade contemporânea de grande parte das naçóes que precisam lidar com a diferença sem prejuízos para as liberdades individuais (TAYLOR, 2000).

Por outro lado, a categoria de pluralidade, tal como definida por Hannah Arendt, parece apresentar um potencial mais fecundo para a compreensão do público no contexto democrático contemporâneo. A grande peculiaridade está no fato de que a autora não considera o espaço público como o lugar em que as diferenças são apenas respeitadas (fundamento da ideia liberal de tolerância), ela apoia-se, sim, na concepção de que a política só existe por meio dessas diferenças, isto é, por meio da pluralidade.

Hannah Arendt, contrapondo-se à perspectiva liberal, retira da diversidade seu caráter privado e a traz para o centro do espaço público. Sua premissa é a de que as diferentes formas de se compreender a realidade, apresentadas em público por cada pessoa, criam uma esfera de proximidade entre os cidadãos - uma vez que todos fazem parte de uma mesma realidade compartilhada -, mas ao mesmo tempo preservam a singularidade de cada um - pois cada pessoa é livre para apresentar sua própria perspectiva a respeito dessa realidade. A política, portanto, nasce da expressão da diferença, sem que isso promova a fragmentação social: ela une e ao mesmo tempo separa as pessoas. Nesse sentido, não é o consenso, não é o conflito e muito menos a homogeneidade o princípio que imprime forma à política, e sim a pluralidade.

Tomar a pluralidade como categoria para pensar o democrático é compatível com a natureza aberta e dinâmica da democracia. Tal perspectiva valoriza a existência de um substrato normativo em comum unindo os cidadãos, mas, do mesmo modo, permite que o sentido da vida coletiva seja continuamente reavaliado e transformado, pois é impossível determinar tanto o conteúdo 
O espaço público e a política moderna: uma análise das perspectivas de Carl Schmitt e Hannah Arendt | Mariah Lança de Queiroz Casséte

como as consequências da ação conjunta. No contexto democrático, o público precisa ser uma categoria plural, capaz de garantir a diferença, a diversidade e a inclusão como princípios centrais de sua configuração e entendimento. $\mathrm{O}$ princípio da pluralidade que encontramos no pensamento de Arendt pode ser um relevante ponto de partida nesse sentido.

\section{Referências}

ARDITI, B. Sobre o político: com Schmitt e apesar de Schmitt. Caderno CRH, Salvador, v. 21, n. 64, p. 423-438, 2008.

ARENDT, H. The promise of politics. New York: Schocken Books, 2005.

A condiçáo humana. Tradução de Roberto Raposo. 10. ed. Rio de Janeiro: Forense Universitária, 2007.

BARRY, B. Political theory, Old and New. In: GOODIN, R.; KLINGEMANN H. (Ed.). A new handbook of political science. Oxford: Oxford University Press, 1998.

BENHABIB, S. The Reluctant Modernism of Hannah Arendt. Lanham, Md.: Rowman \& Littlefield, 2003.

FERREIRA, B. O risco do político: crítica ao liberalismo e teoria política no pensamento de Carl Schmitt. Belo Horizonte: Editora da UFMG, 2004.

GALSTON, W. A. The practice of liberal pluralism. Cambridge: Cambridge University Press, 2005.

LAFER, C. Hannah Arendt: pensamento, persuasão e poder. Sáo Paulo: Paz e Terra, 2003.

LEYDET, D. Crise da representação. In: CARDOSO, S. (Org.). Retorno ao republicanismo. Belo Horizonte: Editora da UFMG, 2004.

PITKIN, H. Attack of the mob: Hannah Arendt's concept of the social. Chicago: University of Chicago Press, 1998.

PREUSS, U. K. Political order and Democracy: Carl Schmitt and his influence. In: LACLAU, E.; MOUFFE, C. (Ed.). The challenge of Carl Schmitt. New York: Verso, 1999.

ROSANVALLON, P. La historia de la palabra democracia en la época moderna. Estudios Políticos, Medellín, n. 28, p. 9-28, enero-junio, 2006.

SCHMITT, C. The crisis of parliamentary democracy. Cambridge: The MIT Press, 1992.

O conceito do político. Chicago: The University of Chicago Press, 1996. 
Ethic of State and Pluralistic State. In: LACLAU, E.; MOUFFE, C. (Ed.). The challenge of Carl Schmitt. New York: Verso, 1999.

Political Theology: four chapters on the concept of sovereignty. Chicago: The University of Chicago Press, 2005.

SCHUMPETER, J. Capitalismo, socialismo e democracia. Tradução de Sérgio Góes de Paulo. Rio de Janeiro: Zahar, 1984.

TAYLOR, C. Argumentos filosóficos. São Paulo: Loyola, 2000.

VILLA, D. Arendt and Heidegger. Princeton: Princeton University Press, 1996.

WEBER, M. A política como vocação. In: Ciência e política: duas vocaçôes. São Paulo: Cultrix, 1970.

WOLIN, S. Hannah Arendt: Democracy and the Political. In: Hannah Arendt: critical essays. HINCHMAN, L. (Ed.). New York: State University of New York Press, 1994.

YOUNG, I. Political Theory: an overview. In: GOODIN, R.; KLINGEMANN H. (Ed.). A new handbook of political science. Oxford: Oxford University Press, 1998.

\section{Public sphere and modern politics: an analysis of the perspectives of Carl Schmitt and Hannah Arendt}

\section{Abstract}

This paper aims to establish a conceptual analysis about the way Carl Schmitt and Hannah Arendt built a political conception based on the idea of the public, contrasting to the private and individualistic logic of modern liberal systems. It is interesting to notice that both authors understand the political as an interaction language to those who live together, and because of that, both authors recognize the importance of public life and the value of the actions developed in this sphere. Despite of this initial convergence, we will point out the way in which each one of them presents a particular perspective through the meaning and the basis of the public sphere. In fact, if in Schmitt's arguments the focus of public life is the national unity and the collective identity, to Hannah Arendt the meaning of public is the fact of plurality and the dialogical practice.

Keyswords: Politics. Public Sphere. Carl Schmitt. Hannah Arendt. 